\title{
Mathematical Modeling of Effluent Quality of Cha-Am Municipality Wastewater Treatment Pond System Using PCSWMM
}

\author{
Anuva Bhowmick, ${ }^{1}$ Kim N. Irvine ${ }^{2}$ and Ranjna Jindal ${ }^{1}$ \\ ${ }^{1}$ Mahidol University, Thailand; ${ }^{2}$ Nanyang Technological University, Singapore.
}

\begin{abstract}
Water quality around Cha-Am, Thailand is of prime concern because of its extensive oceanfront beach area. Cha-Am uses an aerated lagoon system consisting of three ponds and a natural wetland to treat the municipal wastewater. A personal computer version of the storm water management model, PCSWMM, was used to simulate the effluent quality of the treatment system. Water quality samplings for total suspended solids (TSS), total Kjeldahl nitrogen (TKN), Escherichia coli (E. coli), chemical oxygen demand (COD), as well as evaporation measurements, were conducted on a bi-weekly basis for three months to calibrate the model. The four ponds were considered as four storage zones in the model. Based on the observed water quality data distribution, Monte Carlo simulation was used (1 000 iterations, 20 times) to get the most probable input concentration for each pond to determine the appropriate treatment fractions for the model. Data on daily inflow rates, pump operation and bathymetric survey also were obtained from the system operator as model input. The dynamic wave method was used with observed inflow rates to generate a continuous water quality simulation from 2015-07-19 to 2015-09-12. Observed mean treatment efficiency was 51.9\%, 77.3\%, 99.6\% and 9.4\% for TSS, TKN, E. coli and COD respectively. Observed concentrations at the outlet ranged between, $10 \mathrm{mg} / \mathrm{L}$ to $25.5 \mathrm{mg} / \mathrm{L}, 0.98 \mathrm{mg} / \mathrm{L}$ to $3.92 \mathrm{mg} / \mathrm{L}, 0.1$ CFU/100 mL to $260 \mathrm{CFU} / 100 \mathrm{ml}$ and $48 \mathrm{mg} / \mathrm{L}$ to $119 \mathrm{mg} / \mathrm{L}$ for TSS, TKN, E. coli and COD respectively. The treatment fraction approach in PCSWWM was able to accurately represent the outlet concentrations of TSS, TKN, E. coli and COD.
\end{abstract}

\section{Introduction}

Adequate sanitation is of global concern and for developing countries it appears as one indicator for the Millennium Development Goals (e.g. Sachs and McArthur 2005; Montgomery and Elimelech 2007; Bartram and Cairncross 2010). Clean water and appropriate wastewater treatment are particularly important in coastal resort areas that depend on water based recreational opportunities (Smith 1991; Mihalic 2000; Roca and Villares 2008). Cha-Am, Thailand is one such coastal community and here the municipality decided to implement an aerated lagoon system to treat its wastewater. Cha-Am is located about $180 \mathrm{~km}$ south of Bangkok (Figure 1). Because of its proximity to the nation's capital it attracts both local Thais as well as international visitors. The area currently is not as densely developed as the nearby resort area of Hua Hin, but it does boast one of the longest (5 km) uninterrupted beach areas in Thailand (Figure 2 below).

However, condominium and gated community buildout is beginning to increase and an important question is whether the current wastewater treatment system can effectively accommodate such development. This question can be explored through the application of mathematical modeling and as a first step in

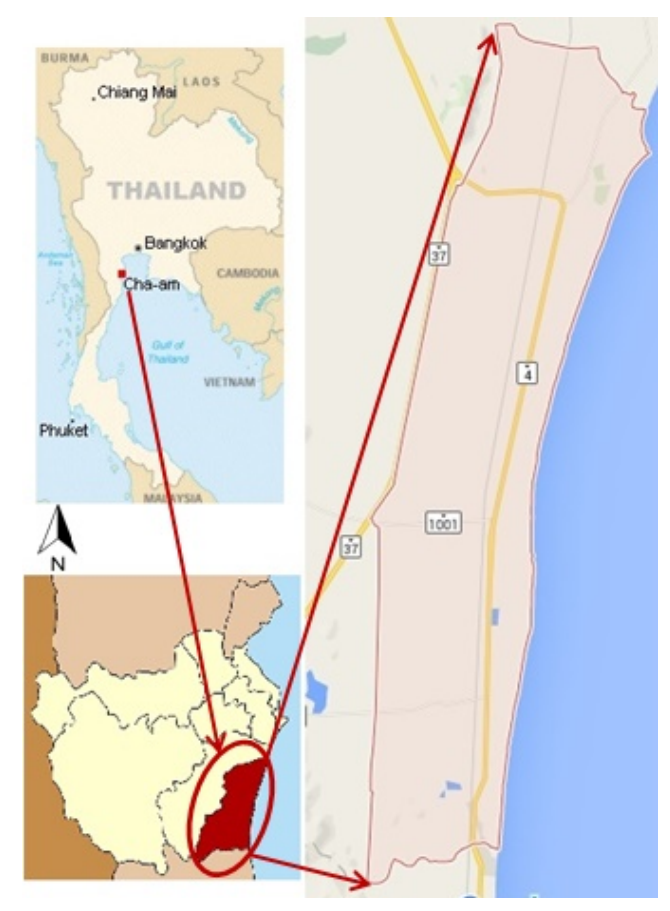

Figure 1 Location of Cha-Am in Thailand.

Bhowmick, Anuva, Kim N. Irvine and Ranjna Jindal. 2017. Mathematical Modeling of Effluent Quality of Cha-Am Municipality Wastewater Treatment Pond System Using PCSWMM. Journal of Water Management Modeling 25:C423.

https://doi.org/10.14796/JWMM.C423 @ CHI 2017. www.chijournal.org ISSN 2292-6062. 
such assessment it is important to confirm that the model adequately reflects the current system performance (Schueler 1987; Hamed et al. 2004; Mjalli et al. 2006; Wang et al. 2012; Sovann et al. 2015, Irvine et al. 2015). As such, the main objective of this research was to calibrate PCSWMM for the current Cha-Am aerated lagoon treatment system configuration and current contributing area conditions, using the treatment fraction approach and a Monte Carlo simulation with a specific focus on total suspended solids (TSS), total Kjeldahl nitrogen (TKN), Escherichia coli (E. coli) and chemical oxygen demand (COD).

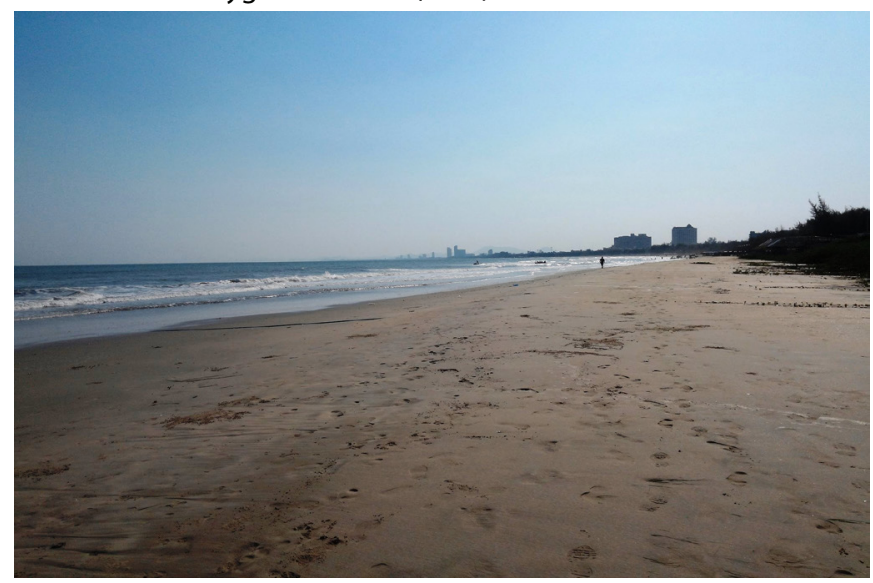

Figure 2 Cha-Am Beach, Thailand.

\section{Methodology}

\subsection{Study Site}

The Cha-Am municipal wastewater treatment system is an aerated lagoon system that receives wastewater and stormwater via the combined sewers that serve an $8 \mathrm{~km}^{2}$ area of commercial and residential land uses near the beach, as well as newer residential land uses adjacent to the lagoons (Figure 3).
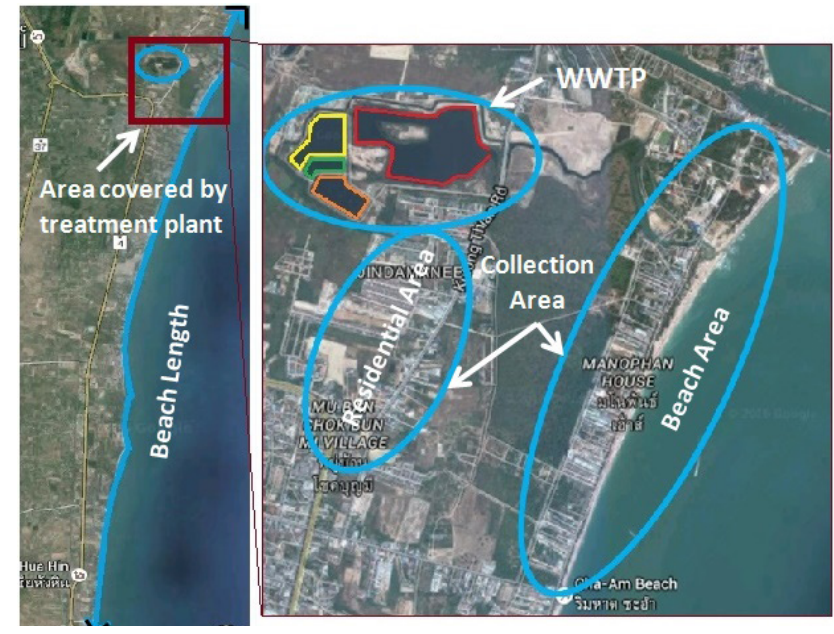

Figure 3 Total beach length under Cha-Am municipality and area coverage by the municipal wastewater treatment plant (WWTP).
The ponds have a total surface area of $0.32 \mathrm{~km}^{2}$ ( 80 acres) and a maximum treatment capacity of $17000 \mathrm{~m}^{3} / \mathrm{d}$. However, the wastewater generation rate averages $\sim 5200 \mathrm{~m}^{3} / \mathrm{d}$ (ONEP Thailand 2014).

The lagoon system incorporates biological processes, aeration, settling, and evaporation in a series of three ponds and a natural wetland to treat the waste (Figure 4).

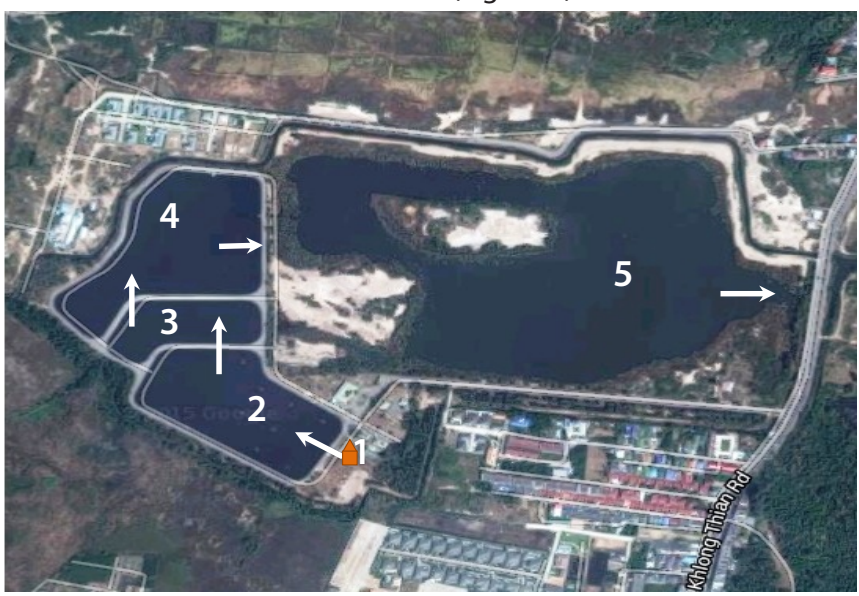

Figure 4 The inflow direction in the wastewater treatment plant (1 main pump station; 2 aeration pond; 3 sedimentation pond; 4 stabilization pond; 5 evaporation pond).

The wastewater from the collection system goes to the first (aeration) pond through a pump station. The surface area of this pond is $40082 \mathrm{~m}^{2}$ with water depth varying between 2.50 $\mathrm{m}$ and $2.85 \mathrm{~m}$. There are eight mechanical aerators distributed around this pond (Figure 5). The aerators are usually operated for two hours every day in the morning to increase and stabilize the oxygen level in the pond.

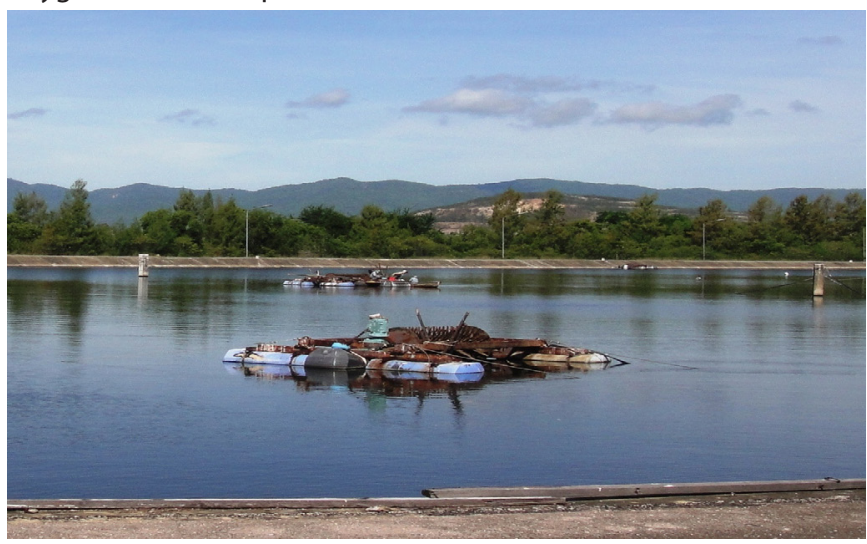

Figure 5 Aeration pond with a mechanical aerator in the foreground.

The second pond is the sedimentation pond (Figure 6). The water from the first pond passes to the second pond through two pipes, each with a diameter of $1.2 \mathrm{~m}$. The surface area of this pond is $16452 \mathrm{~m}^{2}$ with water depth that varies between $2.29 \mathrm{~m}$ and 2.5 $\mathrm{m}$. Sludge from the effluent of the aeration pond is settled here. 


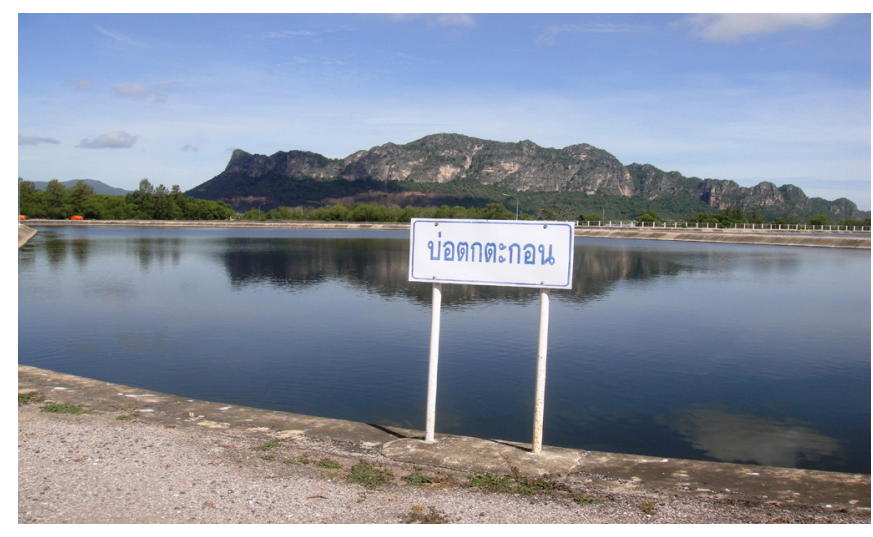

Figure 6 Sedimentation pond.

The third pond is the stabilization pond (Figure 7). With a surface area of $48522 \mathrm{~m}^{2}$, it is used as a polishing unit to improve effluent quality before discharging to the natural wetland. The depth of water varies in this pond between $1.69 \mathrm{~m}$ and $1.80 \mathrm{~m}$.

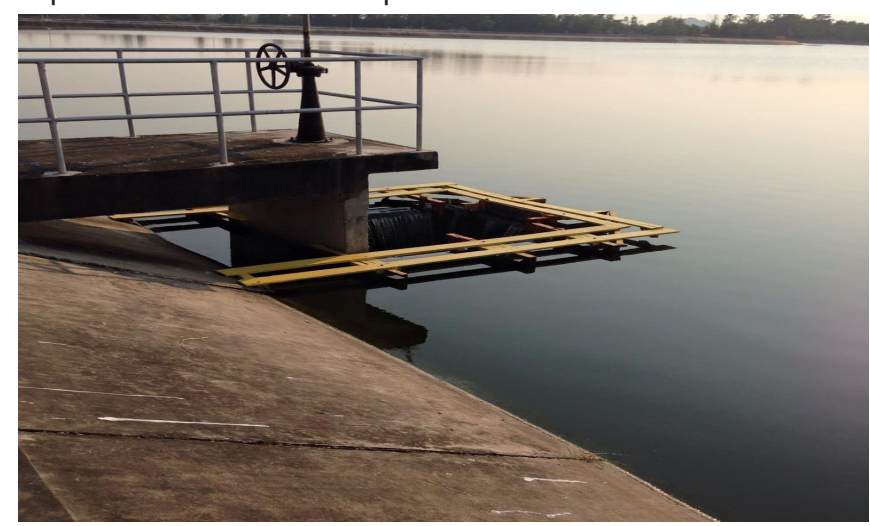

Figure 7 Stabilization pond with effluent chamber (foreground) connecting to the evaporation pond

The fourth pond is the evaporation pond (Figure 8), which has a surface area of about $218546 \mathrm{~m}^{2}$. The design of the entire system is such that much of the loss of water from the system will be via evaporation from the four ponds. However, at the outlet of the wetland, treated flow does discharge down a small stream to the Gulf of Siam (and within the general beach area).

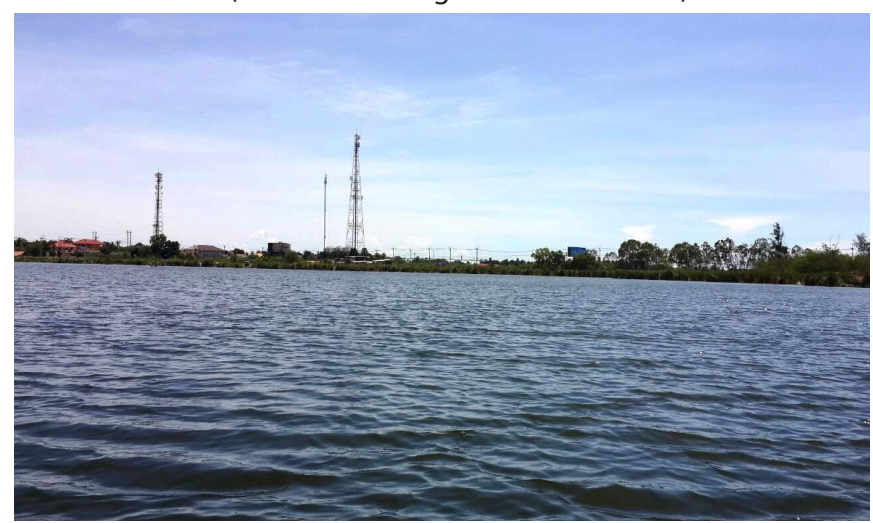

Figure 8 Evaporation pond.

\section{Collection System and Pump Operations}

Cha-Am is serviced by a combined sewer system and the wastewater from the area contributing to the aerated lagoon system first enters into the main pumping station through a bar screen to trap the gross solids. This station consists of four pumps, each $0.3048 \mathrm{~m}$ (12 in.) in diameter with a capacity of $\sim 280 \mathrm{~m}^{3} / \mathrm{h}$. The inflow rates vary from peaks of approximately $3000 \mathrm{~m}^{3} / \mathrm{d}$ to $5000 \mathrm{~m}^{3} / \mathrm{d}$ for the dry season and $>10000 \mathrm{~m}^{3} /$ day for the rainy season. The pump operation (start and stop) is controlled by five float switches based on the level control. The first pump is run for $30 \mathrm{~min}$, turns off, and then the second pump starts automatically and so on. This sequential operation is meant to minimize overall wear of the individual pumps.

\subsection{Data Collection and Processing}

\section{Flow Data Collection Process}

While the municipality monitors inflow rates to the aerated lagoon system, manual measurement of the outflow at the treatment lagoon was necessary. The manual measurement was done using the area-velocity method with a Global Waters Model FP101 velocity meter on four different sampling dates (from 201508-22 to 2015-09-12) to compare with the inflow.

\section{Evaporation Measurement Process}

A volume of water was taken from the evaporation (fourth) pond and was placed in a Styrofoam cooler, to minimize sensible heat exchange from the ground (Figure 9). The water level and water temperature were monitored on an hourly basis through daylight hours on five different dates, August through September.

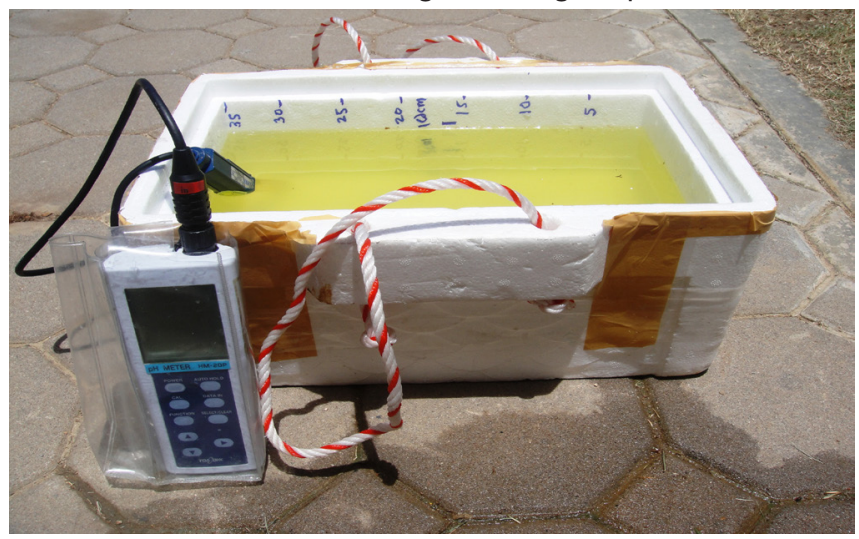

Figure 9 Evaporation rate measurements.

We compared the measured evaporation rates with the results from three empirical formulae (Singh 1997) as follows:

$$
E_{L}=K \mathrm{f}(u)\left(e_{w}-e_{a}\right)
$$

(also known as Dalton's formula) where:
$E_{L}=$ lake evaporation $(\mathrm{mm} / \mathrm{d})$,
$K=$ an empirical coefficient,
$f(u)=$ wind speed correction function, 


$$
\begin{gathered}
e_{w}=\begin{array}{c}
\text { saturation vapour pressure at the water surface } \\
\text { temperature (mm mercury), and }
\end{array} \\
e_{a}=\begin{array}{l}
\text { actual vapour pressure of the overlying air at a } \\
\text { specified height (mm mercury). }
\end{array}
\end{gathered}
$$

$E_{L}=K_{M}\left(e_{w}-e_{a}\right)\left(1+u_{9} / 16\right)$

(also known as Meyer's formula) where:

$u_{9}=$ monthly mean wind velocity $\sim 9 \mathrm{~m}$ above ground, and

$K_{M}=$ coefficient of 0.50 for shallow waters.

$E_{L}=0.771\left(1.465-0.000732 P_{a}\right)\left(0.44+0.0733 u_{0}\right)\left(e_{w}-e_{a}\right)$

(also known as Rohwer's formula) where:

$P_{a}=$ mean barometric pressure ( $\mathrm{mm}$ mercury), and

$u_{0}=$ mean wind velocity in $\mathrm{km} / \mathrm{h}$ at ground level.

Evaporation rates from Equations 1 to 3 were converted to $\mathrm{m} / \mathrm{d}$ for consistency in mass balance calculations and it was found that estimates from Rohwer's formula $(0.01 \mathrm{~m} / \mathrm{d})$ were closest to the measured rates $(0.012 \mathrm{~m} / \mathrm{d}$, Figure 10$)$. As such, this formula was used to estimate evaporation rates for the model simulation period.

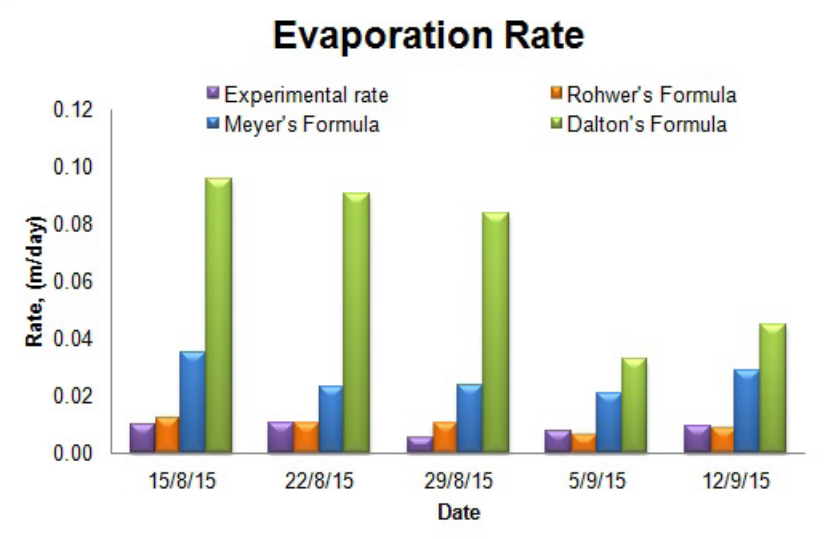

Figure 10 Comparison of measured (experimental) and calculated evaporation rates.

\section{Water Depth Measurement}

Two Yellow Spring Instruments (YSI 6920) sondes were placed in the aeration pond and sedimentation pond to monitor water quality parameters at 30 min time steps. However, the sondes also measure water depth above the sensors and to understand water depth variation with time, we used the sonde data.

\section{Water Quality Sampling}

All samples ( 60 samples for TSS, TKN and COD, and 107 samples for E. coli) were collected at the inlets and outlets of the different ponds (Figure 11). The water quality analytical work was done by another member of our research team, Ms. Kanha But, at the Environmental and Water Resources Engineering Laboratory,
Mahidol University, and is reported in detail elsewhere (But et al. 2016). Analysis results were used as the model input for calibration purpose.

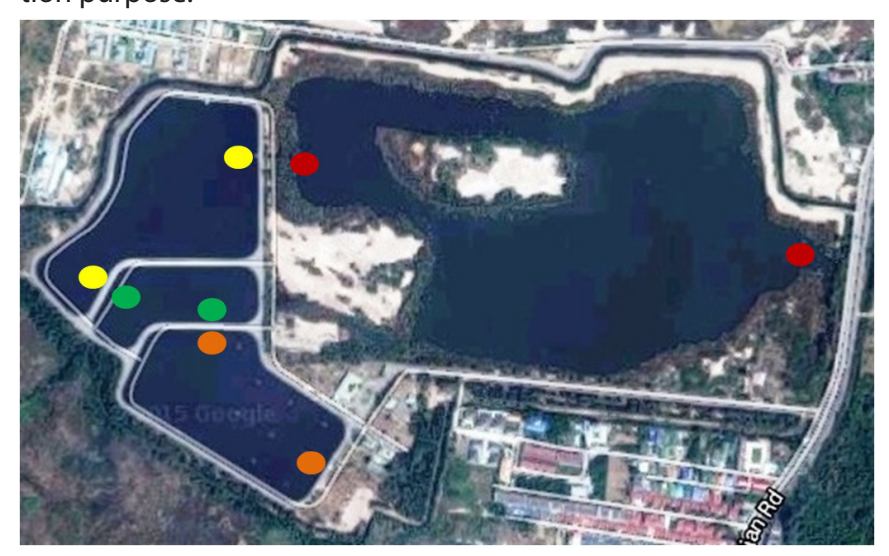

Figure 11 Sampling locations (the same color dots indicate the inlet and outlet of each pond).

\subsection{PCSWMM Modeling Approach}

For the development of the model, the four ponds were divided into four storage zones (Z1 through Z4). All the generated wastewater conveyed through the collection system comes to the pumping station (represented as MPS in the model, Figure 12) via junction J. From here the wastewater is pumped to the pond $Z 1$. The effluent of $Z 1$ (the aeration pond) enters into $Z 2$ (the sedimentation pond) via conduit $C 1$. The effluent of $Z 2$ enters into $Z 3$ (the extended aeration pond) via conduit C2. The effluent of Z3 gets released into Z4 (the evaporation pond) through conduit C3. Finally, the effluent of Z4 either flows through another conduit (C4) and is released into a canal at the outfall discharge point (OF) or evaporates (of course, evaporation also can occur from the other ponds). Effluent released to the canal flows towards the sea, the Gulf of Siam (Figure 3 above and Figure 12).

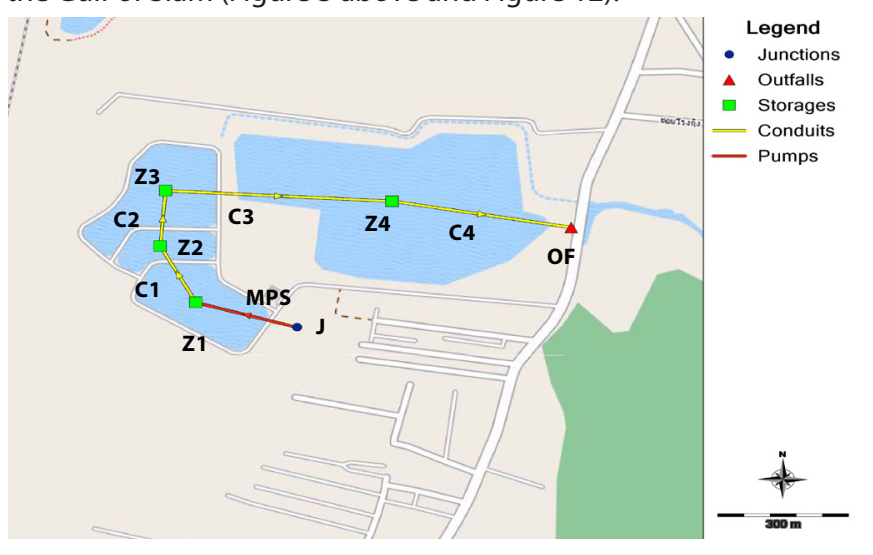

Figure 12 Model layout of the Cha-Am WWTP.

All the data related to inflow rates (2014-10 to 2015-09, Figure 13), pond volume and pump operation were collected from the plant operators to generate the average inflow and daily 
inflow patterns (Figure 14), storage curves (e.g. Figure 15) and the pump curve (Figure 16) respectively.

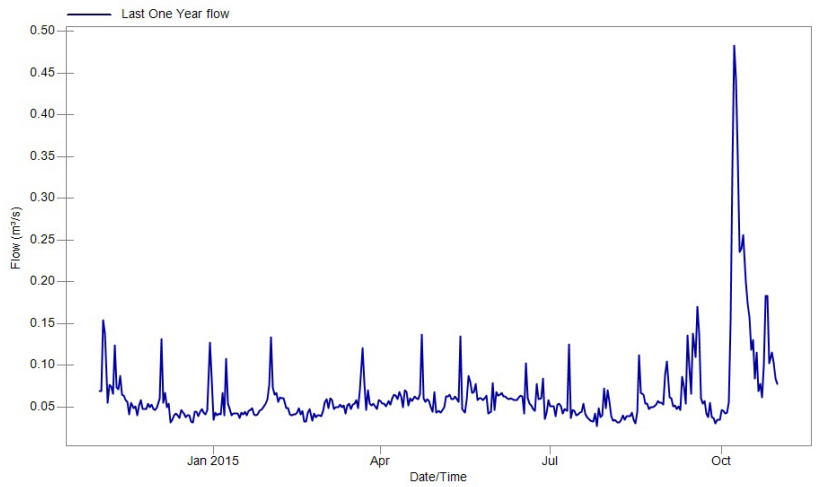

Figure 13 Inflow rate of $1 \mathrm{y}$.
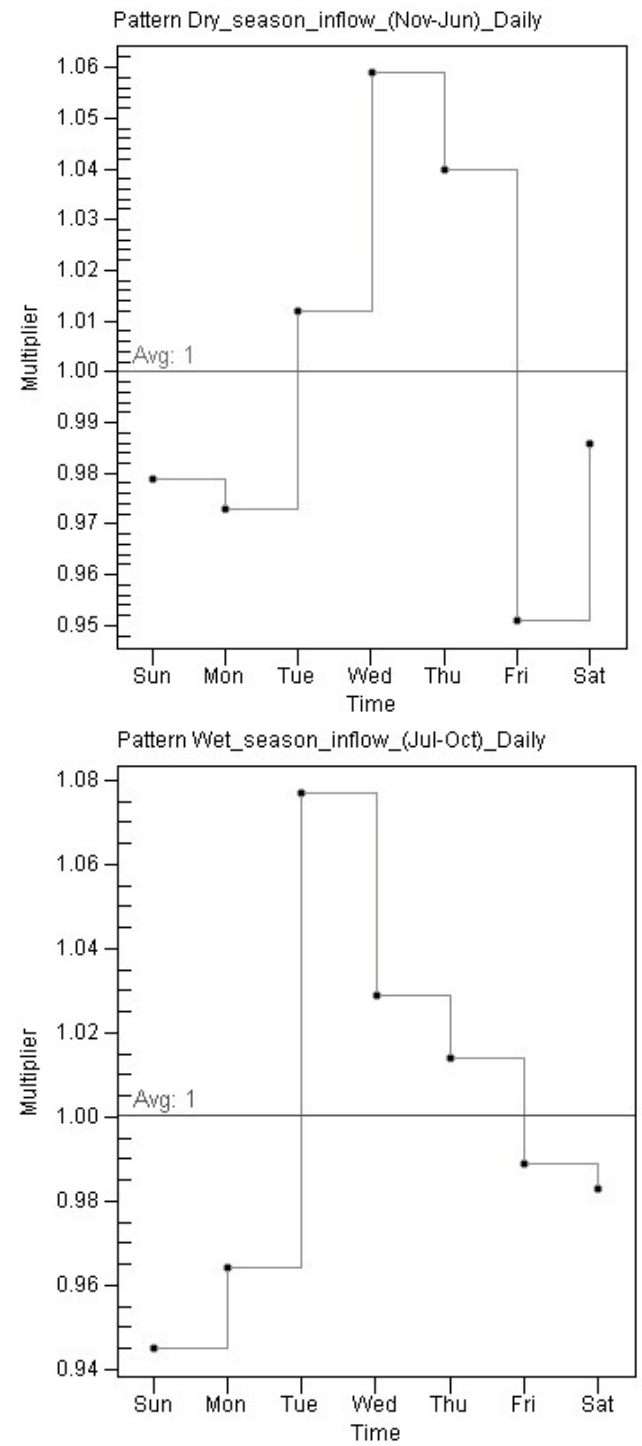

Figure 14 Daily inflow pattern: upper, dry season; lower, wet season.

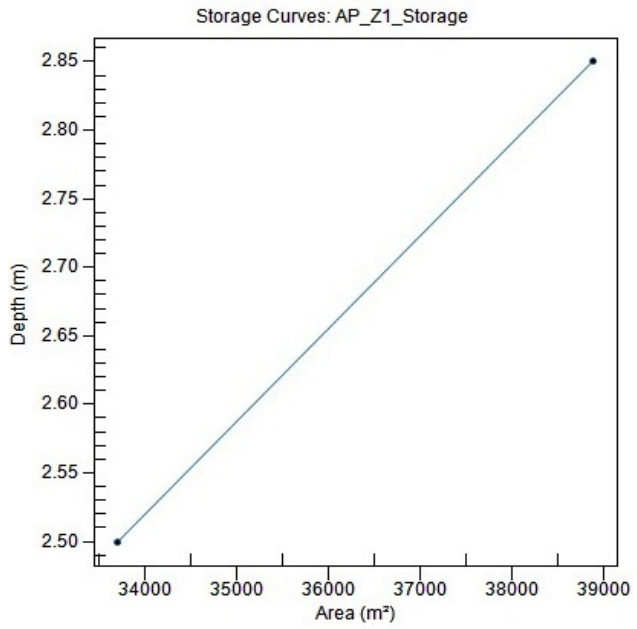

Figure 15 Storage curve for aeration pond.

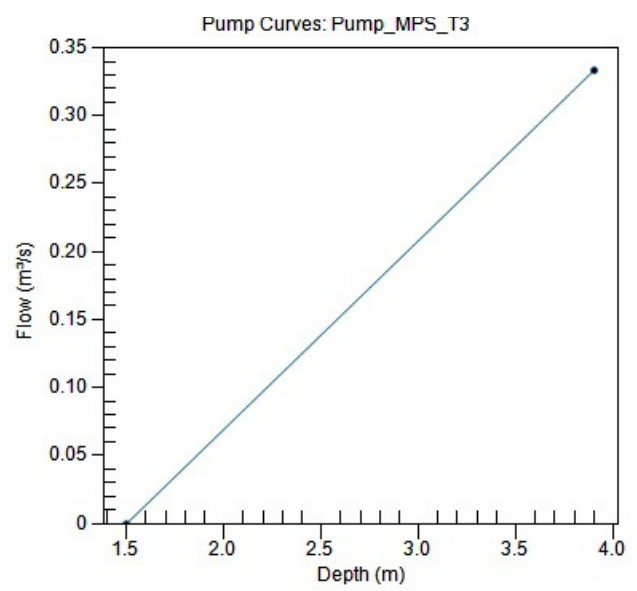

Figure 16 Pump curve.

\section{Treatment Equation Using Monte Carlo Simulation}

Water quality treatment within each pond can be represented using a decay rate approach (e.g. Newman et al. 2000; James et al. 2010), but in this study we took the fractional removal approach (James et al. 2010). The fractional removal approach for each pond generally represents pollutant removal as a function of TSS:

$$
R=0.25 \text { or } R=0.75 \times R \_T S S
$$

where:

$$
R=\text { removal fraction. }
$$

Observed concentrations for each pond could have been represented by a standard arithmetic mean concentration. However, there was some variability in the data from week to week, and also depending on storm events (But et al. 2016).Therefore we used a Monte Carlo simulation to select a most probable observed value based on the measured data.

Sampling is a process where a subset of data (the sample) is chosen out of a large population (e.g. water, air, waste) to explore 
the nature of the entire population. That means a sample should represent the characteristics of the population as a whole. But sampling does not always provide a good estimate of the population. If the data distribution is known or can be approximated then we can incorporate probability into the sampling process, which is known as Monte Carlo sampling.

To do Monte Carlo analysis, first all the observed concentrations were binned into three ranges using the WEKA software (version 3.8.0). Then the probability distributions of the observed concentrations of pollutants were divided into three ranges and a range of probability was chosen by generating a random number between 0.0 and 1.0. For each selected range a concentration value was chosen by taking the average of the distribution within the corresponding range, which is finally treated as the selected pollutant concentration. To get a more realistic value, 1000 iterations for 20 times were done following the flowchart given in Figure 17. After that, to find out the most probable inlet concentration for each pond to determine the fraction of the treatment function, the average of the 1000 iterations for 20 times was taken (Raychaudhuri 2008).

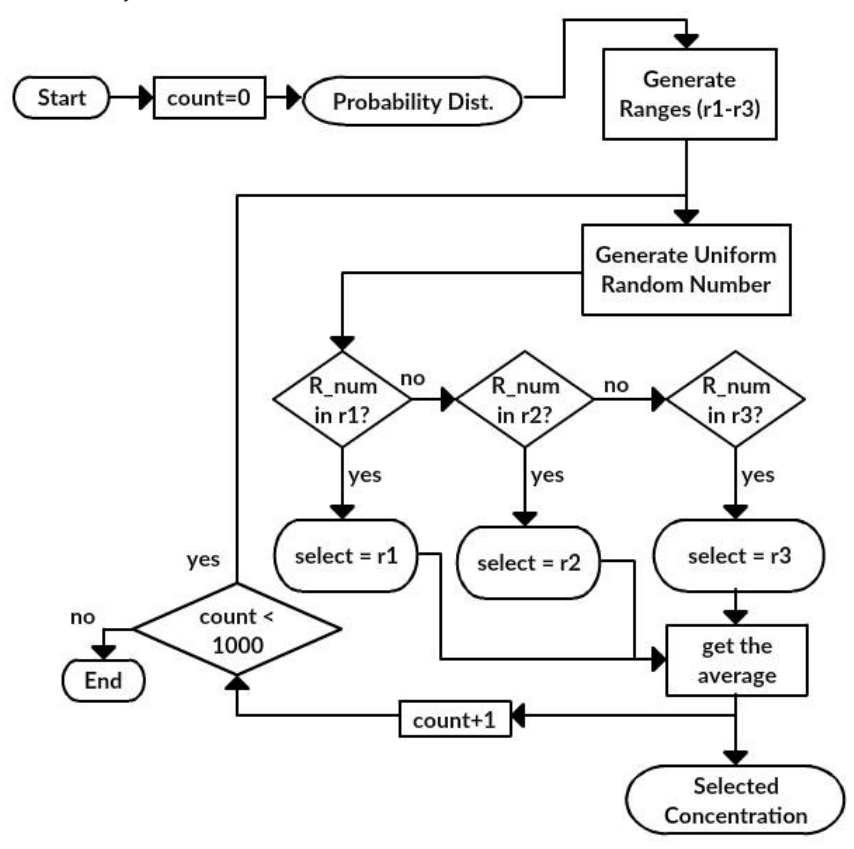

Figure 17 Flowchart of sampling process.

\section{Results and Discussions}

\subsection{Modeled Treatment Efficiency}

Model results for the period 2015-07-19 to 2015-09-12 are shown in Figures 18 through 21 below. The modeled mean concentrations are compared to the mean most probable observed values, based on the Monte Carlo simulations.

In Figure 18 the model predicted mean TSS concentrations that were a bit higher than those observed for the first two ponds. For the last two ponds the modeled values were respectively near the observed concentrations. The observed treatment efficiency for TSS was 51.9\%. The modeled treatment efficiency for TSS was $\sim 66.8 \%$ whereas the probable observed treatment efficiency was $53.4 \%$.

TSS

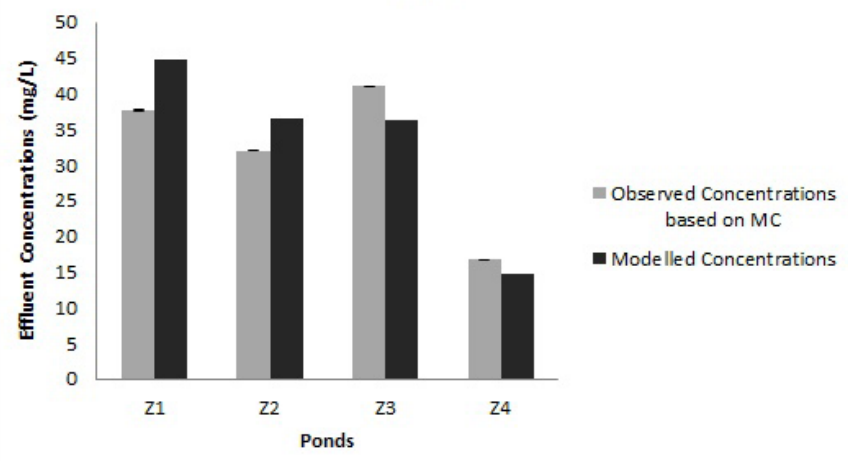

Figure 18 Modeled averaged value compared to the probability based mean observed value (the thin vertical lines represent the standard deviation of the probable observed values of TSS concentration).

In the case of TKN it was found that for all the ponds the model predicted values that were close to the probable observed values (Figure 19). The observed treatment efficiency for TKN was about $77.3 \%$. According to the model prediction, the treatment efficiency of the system for average TKN concentration was about $78.7 \%$ whereas the probable observed efficiency was $77.9 \%$.

TKN

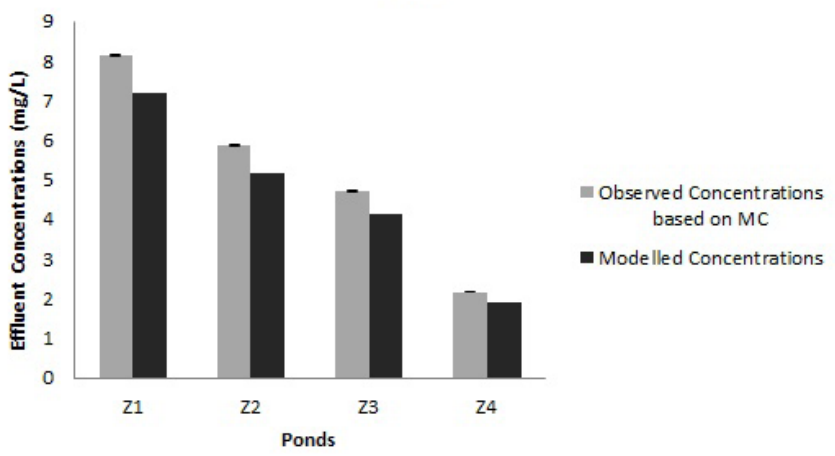

Figure 19 Modeled averaged value compared to the probability based mean observed value (the thin vertical lines represent the standard deviation of the probable observed values of TKN concentration).

The observed efficiency in treating E. coli was 99.6\%. Model predictions for the first two ponds were higher than the range of observed concentrations, but the model predicted concentrations were close to the probable observed values for the last two ponds (Figure 20). It should be noted that observed E. coli in the final pond was quite variable and probably increased slightly from pond 3 due to human activity and wildlife inputs to the natural wetland. 


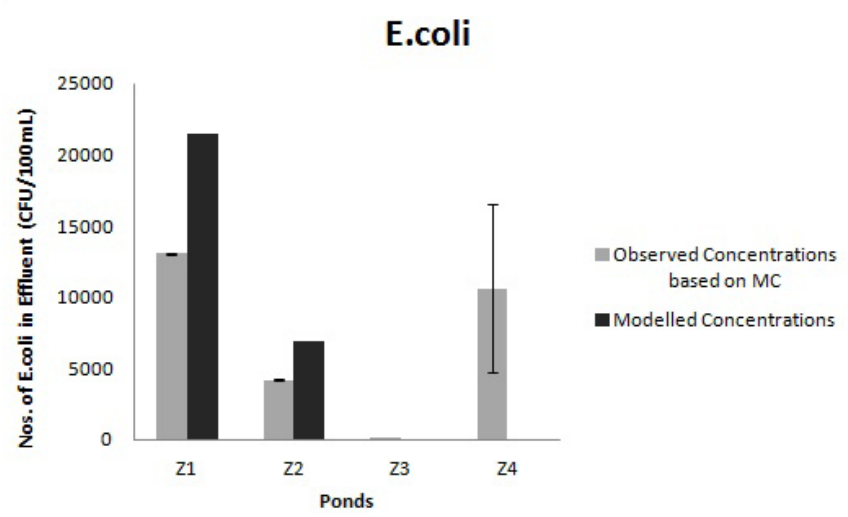

Figure 20 Modeled averaged value compared to the probability based mean observed value (the thin vertical line represent the standard deviation of the probable observed values of $E$. coli colonies).

The model prediction for COD concentration for all ponds was less than the probable observed values, but in general agreement (Figure 21). The observed efficiency in COD removal was 9.4\%. The model predicted COD treatment efficiency was $16.6 \%$ whereas the probable observed efficiency was $12.9 \%$.

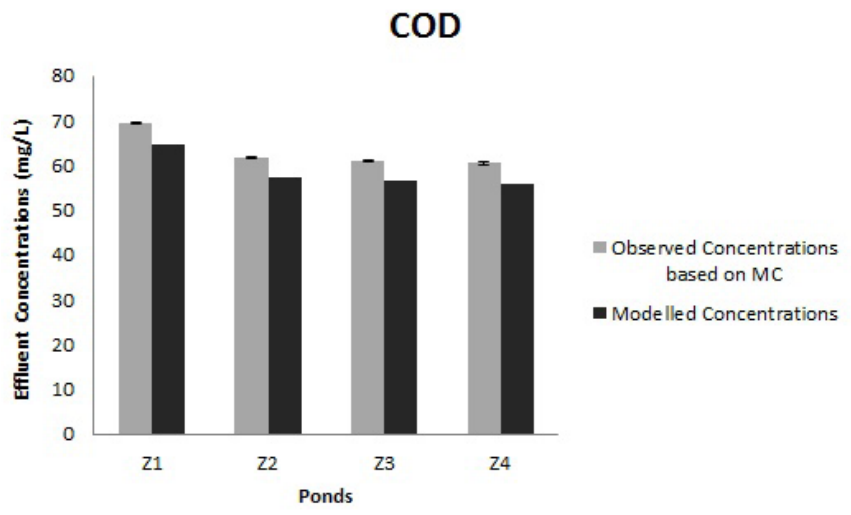

Figure 21 Modeled averaged value compared to the probability based mean observed value (the thin vertical lines represent the standard deviation of the probable observed values of COD concentration).

\subsection{Evaporation Estimates}

Though it was not our objective to measure evaporation at the beginning of the study, since the treatment plant operators indicated that most of the treated wastewater is evaporated from the system, we also considered evaporation measurement in order to investigate the issue. Furthermore, the evaporation measurements helped us conduct a mass balance calculation to help ensure that model inputs and outputs were of the correct order of magnitude. We used an evaporation rate of $0.01 \mathrm{~m} / \mathrm{d}$ (from Rohwer's formula, Section 2.2) as the representative evaporation rate for the mass balance calculations. The rate of water loss from each pond is shown in Table 1.

Table 1 Loss of water from each pond due to evaporation.

\begin{tabular}{lccccc}
\hline \multicolumn{1}{c}{ Ponds } & $\begin{array}{c}\text { Water depth } \\
(\mathrm{m})\end{array}$ & $\begin{array}{c}\text { Area } \\
\left(\mathrm{m}^{2}\right)\end{array}$ & $\begin{array}{c}\text { Total volume } \\
\left(\mathrm{m}^{3}\right)\end{array}$ & $\begin{array}{c}\text { Evaporation rate } \\
(\mathrm{m} / \mathrm{d})\end{array}$ & $\begin{array}{c}\text { Water loss } \\
\left(\mathrm{m}^{3} / \mathrm{d}\right)\end{array}$ \\
\hline 1. Aeration & 2.85 & 40082 & 114234 & 0.01 & 401 \\
2. Sedimentation & 2.5 & 16452 & 41130 & & 165 \\
3. Stabilization & 1.80 & 48522 & 87340 & & 485 \\
4. Evaporation & 2.0 & 218546 & 437092 & & 2185 \\
\hline
\end{tabular}

Table 1 indicates that about $3236 \mathrm{~m}^{3} / \mathrm{d}$ water was evaporated from the system, which was even sometimes greater than the daily inflow. The average inflow for the study period was 4364 $\mathrm{m}^{3} / \mathrm{d}$. Based on this calculation it would seem that most of the inflow would be evaporated and there would be little outflow from the system. However, based on our effluent measurements at the discharge canal, we found that the effluent flow was slightly higher than the experimental one.

Therefore, to scrutinize this further, we considered the rainfall amount for the entire study period. Unfortunately, since Cha-Am municipality does not maintain any rain gauges, we had to use the rainfall data from Hua Hin district which is $25 \mathrm{~km}$ away from Cha-Am. Total rainfall at Hua Hin from 2015-07-19 to 2015-09-12 was $292 \mathrm{~mm}$. We assumed that all the four ponds received the same amount of rainfall and calculated the volume of received water due to rainfall as:

Total area of four ponds $=323602 \mathrm{~m}^{2}$. Total rainfall depth $=0.292 \mathrm{~m}$.

Volume of rainfall received by the ponds $=$ (pond area $\times$ total rainfall depth) $=94492 \mathrm{~m}^{3}$

Then we considered 44 days, assuming there was evaporation (i.e. 44 days where there was no rainfall), and calculated the volume of water loss due to evaporation as:

Total days of evaporation (days without rain) $=44$ days;

Evaporation per day $=0.01 \mathrm{~m}$

Total area of four ponds $=323602 \mathrm{~m}^{2}$

Volume of water loss due to evaporation from the ponds = (pond area $\times$ total days of evaporation $\times$ evaporation rate) $=142385 \mathrm{~m}^{3}$.

Essentially, then, the combination of rainfall input and the inflow to the ponds would be partially balanced by the evaporation loss. The remaining rainfall and the inflow resulted in a slightly higher average outflow at the effluent discharge point. The sonde depth data also showed no extreme fluctuations in water levels within the study period, so storage change was minimal.

\section{Conclusions}

PCSWMM was used to represent the effluent quality of the ChaAm aeration lagoon treatment system under existing conditions. 
The model results generally were similar to the observed water quality in each pond. Based on the reasonable model results for current conditions, the model can be used with some confidence to assess the impact of future development scenarios and population change on the pond operation at a planning level. Design and operation decisions can be made by simulating the physical plant operation, which is cost effective and time saving (DeVries and Hromadka 1993; Simachaya 2002; Rees and Schoen 2009; Fan et al. 2015). The next step in this research will be to link the pond system with the collection system represented by PCSW$\mathrm{MM}$ and explore the impact of future development scenarios on treatment efficiency.

\section{Acknowledgments}

We are grateful for the partial scholarship from Environmental and Water Resources Engineering (International Program), Mahidol University to support this research. We also thank Computational Hydraulics Int. for the software support through the $\mathrm{CHI}$ University Grant Program.

\section{References}

Bartram, J. and S. Cairncross. 2010. “Hygiene, Sanitation, and Water: Forgotten Foundations of Health." PLOS Medicine 7 (11): 1-9.

https://doi.org/10.1371/journal.pmed.1000367.

But, K., R. Jindal, K. N. Irvine and N. Surinkul. 2016. “Investigations of Effluent Quality of Cha-Am Municipality Wastewater Treatment Pond System." 5th International Conference on Sustainable Energy and Environmental Sciences (SEES 2016). https://doi.org/10.5176/2251-189X_SEES16.8.

DeVries, J. J. and T. V. Hromadka. 1993. “Computer Models for Surface Water." In Handbook of Hydrology, edited by D. Maidment. New York: McGraw-Hill.

Fan, F. M., A. S. Fleischmann, W. Collischonn, D. P. Ammes and D. Rigo. 2015. “Large-Scale Analytical Water Quality Model Coupled with GIS for Simulation of Point Sourced Pollutant Discharges". Environmental Modeling \& Software 64:58-71. https://doi.org/10.1016/j.envsoft.2014.11.012.

Hamed, M. M., M. G. Khalafallah and E. A. Hassanien. 2004. “Prediction of Wastewater Treatment Plant Performance Using Artificial Neural Networks." Environmental Modeling \& Software 19:919-28.

Irvine, K. N., C. Sovann, S. Suthipong, S. Kok and E. Chea. 2015. "Application of PCSWMM to Assess Wastewater Treatment and Urban Flooding Scenarios in Phnom Penh, Cambodia: A Tool to Support Eco-City Planning." Journal of Water Management Modeling 24:C389. https://doi.org/10.14796/JWMM.C389.

James, W., L. E. Rossman and W. R. C. James. 2010. User's Guide to SWMM5, 13th ed. Guelph: CHI Press.
Mihalic, T. 2000. “Environmental Management of a Tourist Destination. A Factor of Tourism Competitiveness." Tourism Management 21:65-78.

Mjalli, F. S., S. Al-Asheh and H. E. Alfadala. 2006.“Use of Artificial Neural Network Black-Box Modeling for the Prediction of Wastewater Treatment Plants Performance." Environmental Management 83:329-38.

Montgomery, M.A. and M. Elimelech. 2007. "Water and Sanitation in Developing Countries: Including Health in the Equation." Environmental Science \& Technology 41 (1): 17-24.

Newman, T., T. A. Orner and E. D. Driscoll. 2000. "SWMM Storage-Treatment for Analysis/Design of Extended-Detention Ponds." Journal of Water Management Modeling R206-17. https://doi.org/10.14796/JWMM.R206-17.

ONEP (Office of Natural Resources and Environmental Policy and Planning). 2014. Environmental Impact Assessment in Thailand. Bangkok: Office of Natural Resources and Environmental Policy and Planning.

Raychaudhuri, S. 2008. "Introduction to Monte Carlo Simulation." Proceedings of the 2008 Winter Simulation Conference, IEEE. https://doi.org/10.1109/WSC.2008.4736059

Rees, P. and J. Schoen. 2009. PCSWMM Evaluation. Amherst, MA: University of Massachusetts, Water Resources Research Center.

Roca, E. and M. Villares. 2008. "Public Perceptions for Evaluating Beach Quality in Urban and Semi-Natural Environments." Ocean \& Coastal Management 51:314-29. https://doi.org/10.1016/j.ocecoaman.2007.09.001.

Sachs, J. D. and J. W. McArthur. 2005. "The Millennium Project: A Plan for Meeting the Millennium Development Goals." The Lancet 365:347-53.

Schueler, T. R. 1987. Controlling Urban Runoff: A Practical Manual for Planning and Designing Urban BMPs. Washington, DC: Metropolitan Washington Council of Governments (MCOG). Publication Number 87703.

Simachaya, W. 2002. "Water Quality Monitoring and Modeling Application in Thailand". Paper presented to the Third World Water Forum Session on Water Quality Monitoring and Modeling-The Present Situation and Partnership in the Future. United Nations University Center in Tokyo, Japan.

Singh ,V. P. and C.-Y. Xu. 1997. "Evaluation and Generalization of 13 Mass-Transfer Equations for Determining Free Water Evaporation." Hydrological Processes 11:311-23.

Smith, R. A. 1991. "Beach Resorts: A Model of Development Evolution." Landscape and Urban Planning 21 (3): 189-210. https://doi.org/10.1016/0169-2046(91)90018-H.

Sovann, C., K. N. Irvine, S. Suthipong, S. Kok and E. Chea. 2015. "Dynamic Modeling to Assess Natural WetlandsTreatment of Wastewater in Phnom Penh, Cambodia: Towards an EcoCity Planning Tool." British Journal of Environment \& Climate Change 5 (2): 104-15. 
Wang, H., E. A. Meselhe, M. G. Waldon, M. C. Harwell and C. Chen. 2012." Compartment-Based Hydrodynamics and Water Quality Modeling of a Northern Everglades Wetland, Florida, USA." Ecological Modeling 247:273-85. 